\title{
ULTRAESTRUTURA COMPARATIVA DOS ESPERMATOZÓIDES DE PORCELLANIDAE (ANOMURA, GALATHEOIDEA: PETROLISTHES E PISIDIA)
}

\author{
Camillo, B.P. ${ }^{1,}$; Miranda, I. ${ }^{1}$; Mantelatto, F.L. ${ }^{2} \&$ Zara, F.J. ${ }^{1}$ \\ 1 Universidade Estadual Paulista "Júlio de Mesquita Filho" (UNESP), Campus Jaboticabal, \\ Laboratório de Morfologia de Invertebrados. \\ ${ }^{2}$ Universidade do Estado de São Paulo (USP), Faculdade de Filosofia, Ciências e Letras de Ribeirão Preto (FFCLRP), \\ Campus Ribeirão Preto, Laboratório de Bioecologia e Sistemática de Crustáceos (LBSC). \\ *Autor correspondente: barbarapcamillo@gmail.com
}

\begin{abstract}
Os espermatozoides de Porcellanidae são alongados e armazenados no interior de espermatóforos. Neste trabalho realizamos a descrição comparativa da ultraestrutura dos espermatozoides de Petrolisthes armatus (Gibbes, 1850), Petrolisthes galathinus (Bosc, 1802) e Pisidia brasiliensis Haig in Rodrigues da Costa, 1968. Os espécimes foram coletados em Ubatuba e São Vicente, São Paulo, por meio de mergulho autônomo e coleta manual. Amostras foram fixadas e processadas de acordo com a rotina de microscopia eletrônica de transmissão. Nas três espécies estudadas, os espermatóforos apresentam a ampola de alongada com parede espessa e granular. O espermatóforo é pedunculado e longo. O opérculo de Pisidia brasiliensis é perfurado, curto e delgado, enquanto nas espécies de Petrolisthes o opérculo perfurado torna-se progressivamente espesso em direção a região posterior formando um domo alto. A câmara perforatorial de Pisidia brasiliensis apresenta formato alongado com ápice arredondado. Nas espécies de Petrolisthes a câmara perforatorial é cilíndrica e alongada, portando na base desta estrutura o material citoplamático é granular eletrondenso. Na região posterior da vesícula acrossomal notam-se dois anéis consecutivos: anel tubular, preenchido por lamelas e túbulos, seguido pelo anel perforatorial posterior eletrondenso e mais dilatado. Nas três espécies o núcleo volumoso está preenchido com cromatina granular e dele partem inúmeros prolongamentos formando braços radiais ou laterais microtubulares em número de quatro em todas as espécies. Em P. brasiliensis um único anel perforatorial está presente, sendo esta a principal diferença entre os gêneros, o que fornece maior suporte ao descrito na literatura. O acrossomo é mais longo e estreito do que o descrito para Pisidia longicornis (Linnaeus, 1767). Em P. armatus a região opercular é mais larga e arredondada, o cone perforatorial eletrondenso é curto e a camada acrossomal interna alcança a camada subopercular, o que não acontece em $P$. galathinus, sendo esta espécie a região opercular estreita e alongada, assim como o cone perforatorial eletrondenso. Desta maneira, $P$. armatus é mais semelhante a Petrolisthes lamarckii (Leach, 1820), diferindo deste somente pela estrutura do septo perforatorial. O espermatozoide de $P$. armatus da costa brasileira é ultraestruturalmente idêntico ao descrito para a costa da Flórida, EUA.
\end{abstract}

Palavras-chave: espermatóforos, pedúnculo, câmara perforatorial, Petrolisthes, Pisidia.

Financiamento: BIOTA-FAPESP (\#2010/50188-8); CAPES Ciências do Mar II (\#1989/2014-23038.004309/2014-51). 